\title{
An unusual and inexplicable ECG pattern in an ostial LAD occlusion
}

Pritesh Parekh, Navin Agrawal, Apurva Vasavada, Mitesh Chauhan

Department of Cardiology, Care Hospital, Surat, Gujarat, India

\section{Correspondence to} Dr Navin Agrawal, drnavinagrawal@gmail.com

Accepted 14 July 2014
CrossMark

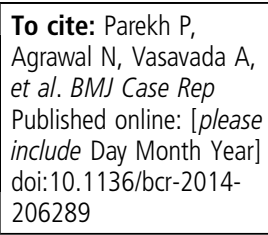

\section{DESCRIPTION}

Traditionally ECG has been the gold standard in culprit vessel localisation in cases with ST elevation myocardial infarction (STEMI). Anterior wall STEMI is most often characterised by the ST elevation in precordial leads which are most often used to diagnose and localise the site of occlusion of the left anterior descending (LAD) artery.

We report an unusual ECG of a 29 -year-old nondiabetic, non-hypertensive male smoker who presented with acute onset chest pain since the past $5 \mathrm{~h}$. The ECG at presentation showed isolated ST

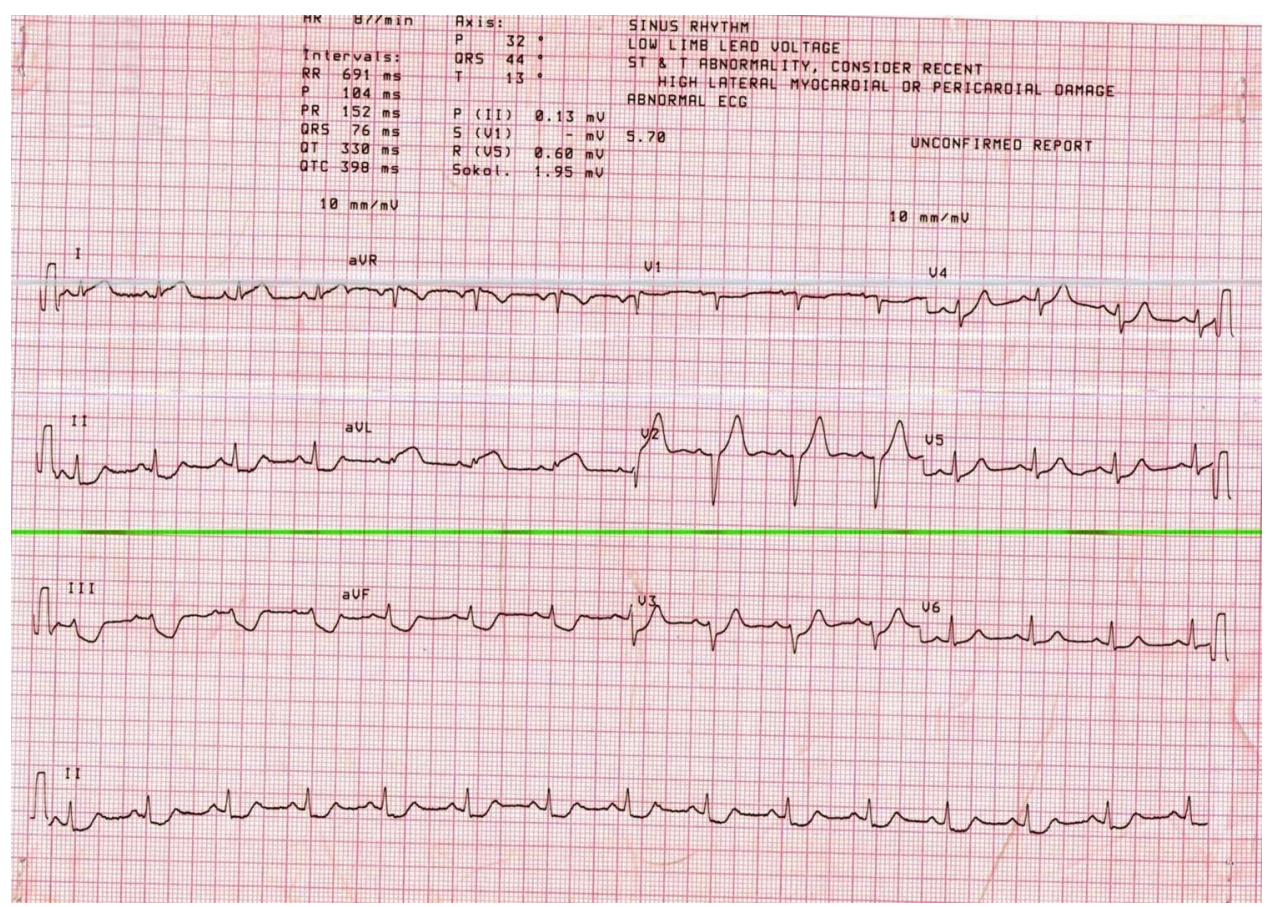

Figure 1 ECG at the time of presentation showing ST elevation in leads I and aVL with no change in precordial leads.

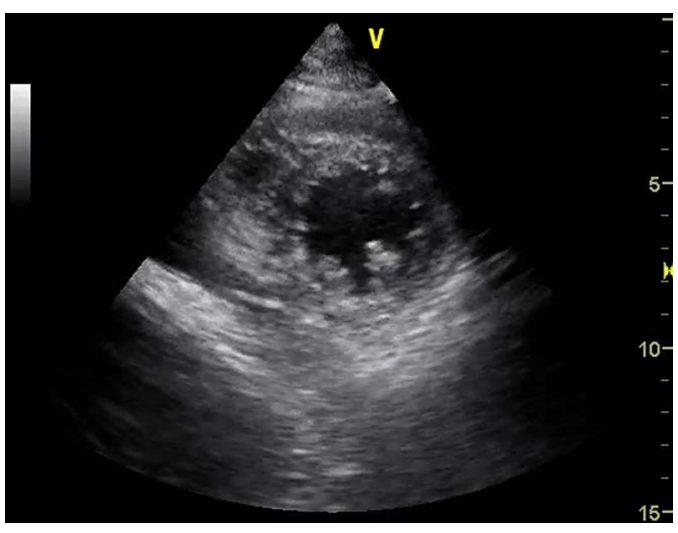

Video 1 Trans-thoracic echocardiogram of the patient in parasternal short axis view showing stunning of large portion of the anterior wall of the patient.

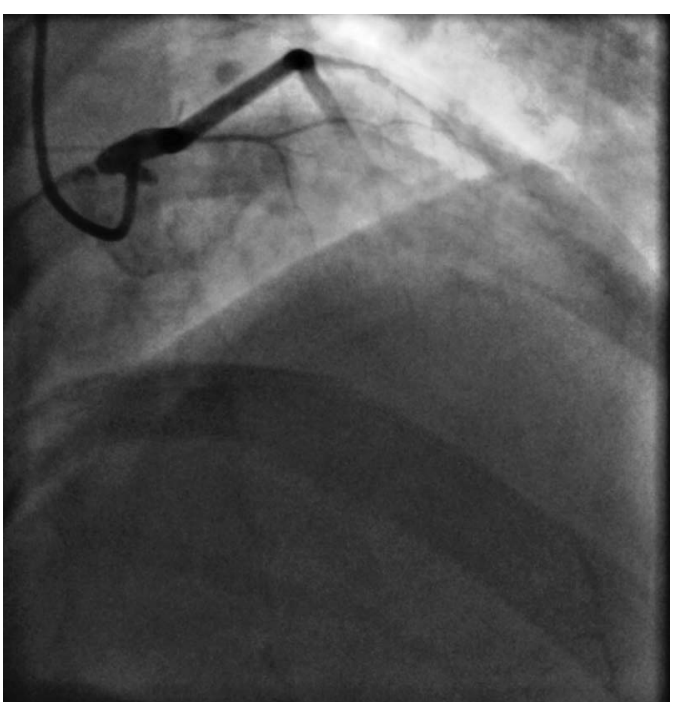

Figure 2 Posteroanterior cranial view of the angiogram showing occlusion of the left anterior descending (LAD). 


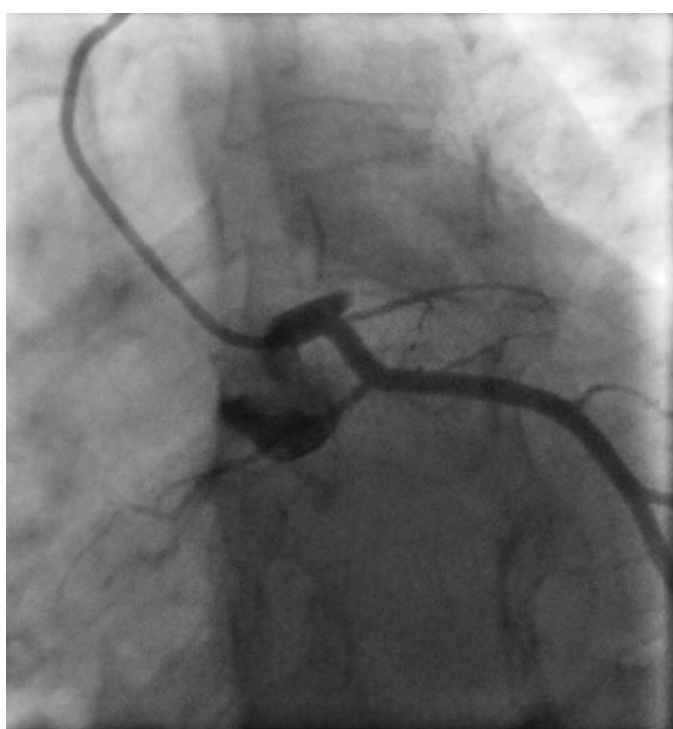

Figure 3 Left anterior oblique caudal view showing ostially occluded left anterior descending (LAD).

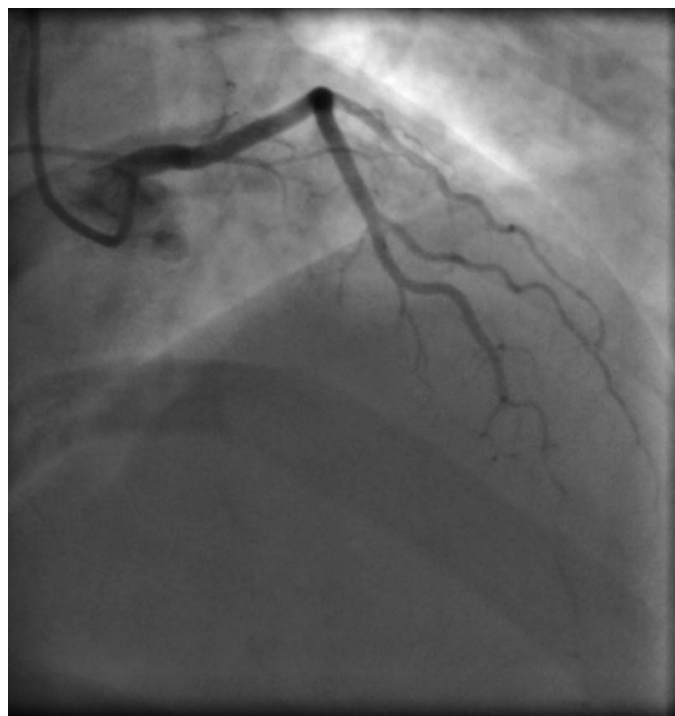

Video 2 PA cranial view of the angiogram showing occlusion of the LAD.

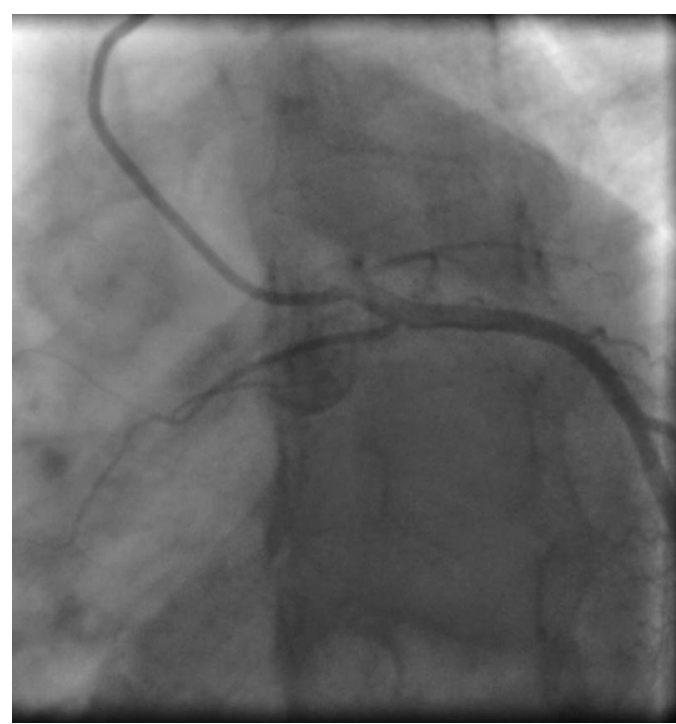

Video 3 LAO caudal view showing ostially occluded LAD.

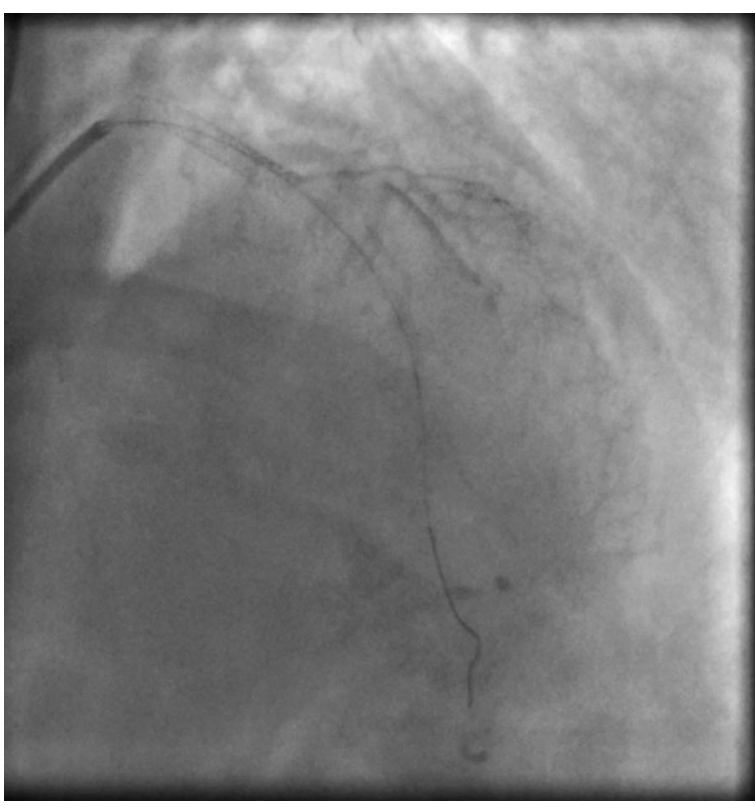

Video 4 PA cranial view after the procedure showing successful result of the procedure.

elevation in leads I and aVL with reciprocal changes in the inferior leads. There was no ST elevation in any of the precordial leads (figure 1). We had suspected an isolated lateral wall infarct possibly related to the occlusion of a diagonal branch of LAD or obtuse marginal branch of the left circumflex artery. The echo images showed diffuse stunning of the anterior wall of the left ventricle which did not corroborate with the ECG findings (video 1). The patient was taken up for primary intervention during which we surprisingly found an ostial occlusion of the

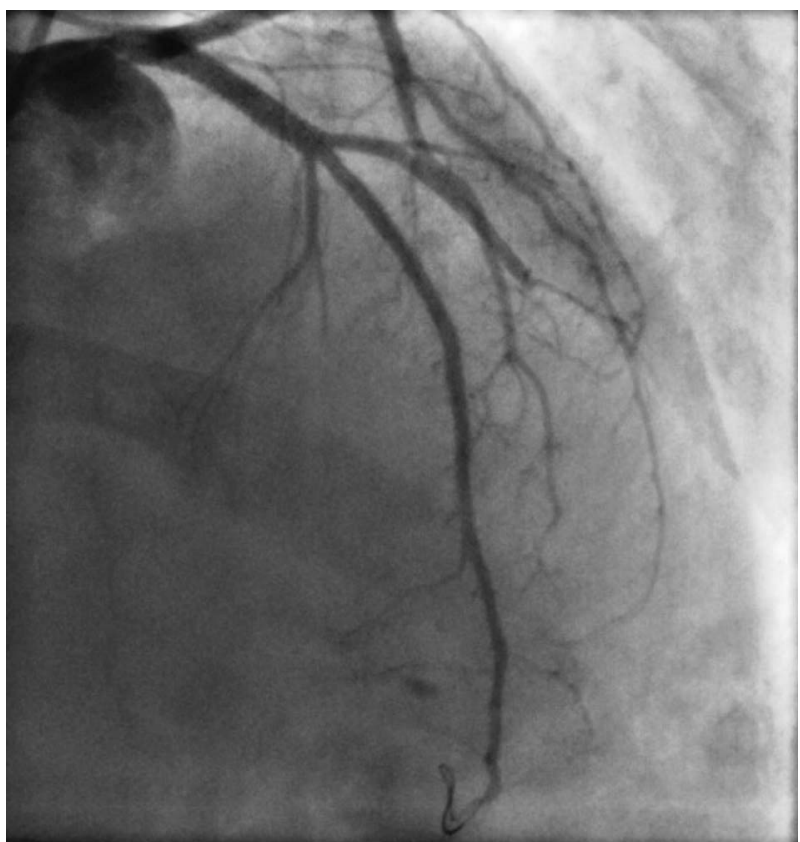

Figure 4 Posteroanterior cranial view after the procedure showing successful result of the procedure with good flow in a normal-sized left anterior descending (LAD). 


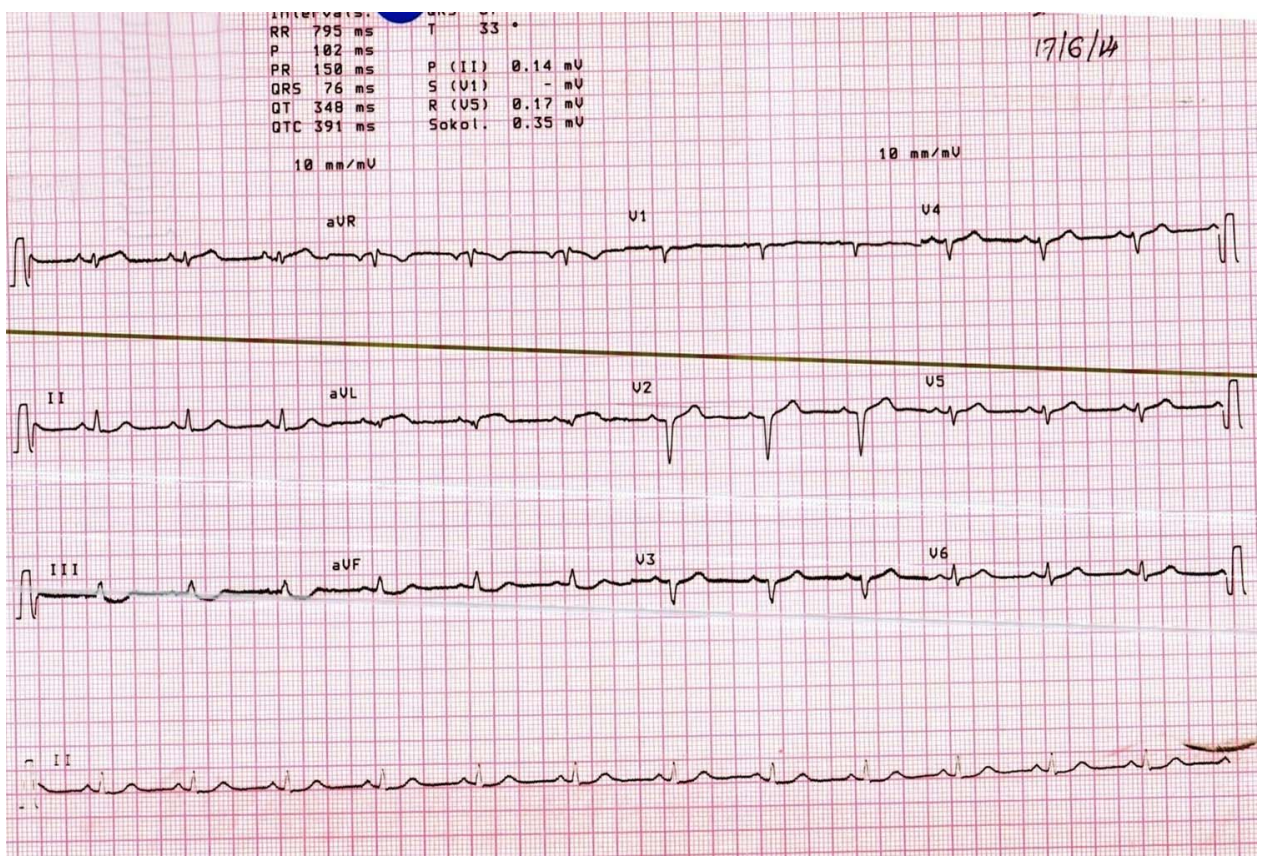

Figure 5 The ECG taken after intervention showing settled ST-T changes.

\section{Learning points}

- Triage and management based on culprit vessel localisation using an ECG although often reliable has several limitations and in a given case it may be completely fallacious.

- ST elevation in precordial leads is a definitive marker of an anterior wall infarction but in rare cases it may be completely absent which should be kept in mind during interpretation of such cases.

- Echo and angiogram should be used in harmony with ECG in risk stratification and in deciding the course and pattern of intervention of patients presenting with ST elevation myocardial infarction. left anterior descending artery (figures 2 and 3, videos 2 and 3). The patient underwent successful angioplasty to the normal-sized culprit vessel (video 4 and figure 4). The ECG changes subsided after the intervention while the echocardiographic picture took some time to improve (figure 5).

Placing reliance on the ECG alone and being less aggressive in intervention in this case considering it to be a small vessel infarct could have been devastating which challenges the credibility of ECG in management and triage of these patients.

Contributors All authors have contributed to drafting and finalising of the manuscript.

Competing interests None.

Patient consent Obtained.

Provenance and peer review Not commissioned; externally peer reviewed.

Copyright 2014 BMJ Publishing Group. All rights reserved. For permission to reuse any of this content visit http://group.bmj.com/group/rights-licensing/permissions.

BMJ Case Report Fellows may re-use this article for personal use and teaching without any further permission.

Become a Fellow of BMJ Case Reports today and you can:

- Submit as many cases as you like

- Enjoy fast sympathetic peer review and rapid publication of accepted articles

- Access all the published articles

- Re-use any of the published material for personal use and teaching without further permission

For information on Institutional Fellowships contact consortiasales@bmjgroup.com

Visit casereports.bmj.com for more articles like this and to become a Fellow 